\title{
As sessões solenes da Faculdade de Filosofia: rituais da comunidade intelectual uspiana
}

\author{
BRUNO BONTEMPI JÚNIOR*
}

\begin{abstract}
Resumo: Este artigo propõe-se a analisar os discursos dos intelectuais da Faculdade de Filosofia, Ciências e Letras da Universidade de São Paulo nas sessões solenes realizadas de 1937 a 1951, destacando sua auto-imagem, memória coletiva e estratégias discursivas diante das questões políticas que desafiavam os intelectuais contemporâneos.
\end{abstract}

\begin{abstract}
The aim of this article is to examine the discourses made by intellectuals of the Faculty of Philosophy, Science and Letters of the University of Sao Paulo in solemn sessions held from 1937 to 1951, highlighting its self-image, collective memory and discursive strategies towards the policy issues that challenged contemporary intellectuals.
\end{abstract}

Palavras-chave: Intelectuais. Discurso. Faculdade de Filosofia, Ciências e Letras da Universidade de São Paulo.

Key words: Intellectuals. Discourse. Faculty of Philosophy, Science and Letters of the University of São Paulo.

Para Randall Collins, os intelectuais têm algo em comum com os demais grupos sociais: como todo grupo local, o agrupamento de que fazem parte liga-se fortemente a símbolos, com relação aos quais seus membros consagram pertencimento e se reportam em suas atividades criativas. ${ }^{1}$ Todavia, diferentemente dos grupos tipicamente locais, tais como tribos ou círculos de amigos, cujos

* Professor e pesquisador do Programa de Estudos Pós-Graduados em Educação: História, Política, Sociedade, da Pontifícia Universidade Católica de São Paulo. E-mail: bontempijr@pucsp.br

1 COLLINS, Randall. The sociology of philosophies. A global theory of intellectual change. Cambridge, Massachusetts and London, England: Harvard University Press, 1998, p. 24-44.

Estudos Ibero-Americanos, PUCRS, v. XXXIV, n. 2, p. 168-187, dezembro 2008 
"objetos sagrados" de culto e referência relacionam-se dominantemente à própria solidariedade e identidade, os intelectuais reivindicam para si símbolos universais e transcendentes, uma vez que constroem sua identidade de grupo com base em pontos de vista abstratos, sejam eles históricos, filosóficos, sociológicos ou psicológicos. Os símbolos dos grupos intelectuais, ou, para usar a linguagem de Collins, os "objetos sagrados" de seus rituais de interação, são criados em comunidades que se alargam internamente, orientando-se para as trocas entre os próprios membros, em vez de fazê-las com estranhos, e assim reivindicam o direito exclusivo de decidir sobre a validade de suas próprias idéias.

Embora Collins eleja como ritual de interação distintivo dos agrupamentos intelectuais as discussões, conferências e comunicações a respeito dos aspectos particulares de suas atividades, ou seja, as situações concretas em que estes se põem à parte das outras redes de vida social para se dirigirem exclusivamente uns aos outros, procura-se aqui compreender como modalidade de ritual de interação intelectual as sessões solenes de formatura da Faculdade de Filosofia, Ciências e Letras da Universidade de São Paulo entre 1937 e 1951 - que não eram propriamente eventos científicos e nem reuniam apenas a comunidade intelectual - por sua importância na consagração de novas gerações aos "objetos sagrados" da comunidade intelectual, mediante construção de emoções distintivas em torno de símbolos e repetição da memória que os amalgama.

Desde 1937, ano em que Júlio de Mesquita Filho proferiu discurso na formatura da primeira turma, as sessões de abertura e de encerramento dos cursos da FFCL-USP tornaram-se intensos "rituais de interação social". Reunindo periodicamente autoridades, personalidades públicas, diretores, mestres e alunos, tais cerimônias congraçavam os participantes em torno de uma causa (o esclarecimento e sua conversão em processo civilizador), de uma identidade (a de intelectuais) e de uma memória (a história reverente da USP e de sua FFCL). Nos rituais de formatura, tendo sido iniciados no idioma comum desde as cerimônias de abertura dos cursos, novos intelectuais eram designados e acolhidos pela comunidade que por meio dele se comunica.

Em 1969, em artigo publicado quando do falecimento de Júlio de Mesquita Filho, o ex-aluno e ex-professor da FFCL Laerte Ramos de Carvalho afirmou que, ao ler o discurso de paraninfo da primeira turma, percebeu que a "inadvertida opção" de ingressar naquela 
escola havia se transformado em uma das mais profundas decisões de sua vida. Compreendera que a opção que fizera e a carreira que escolhera transcendiam as limitadas esferas do exercício profissional para se transformarem na missão elevada de promover, com seus colegas, "o início da revolução espiritual brasileira, base e pressuposto da revolução nacional pela educação". ${ }^{2}$ A leitura do discurso teria sido como uma iniciação, pela qual pôde sair do horizonte limitado e mundano da aspiração imediata a uma carreira profissional para "entrar no círculo das coisas sagradas", no qual se admitem apenas os que, substancialmente transformados, aceitam dar as costas ao domínio proibido. ${ }^{3}$

Para os formandos da primeira turma, a emoção da iniciação fora sentida na cerimônia em que ouviram a mensagem lida pelo licenciado Raul Ferraz de Mesquita, os discursos de Antônio de Almeida Prado, diretor da Faculdade de Filosofia, as falas de João Cruz Costa, primeiro aluno matriculado e orador da turma, e do paraninfo Mesquita Filho. O tom geral é de júbilo religioso, ordenação dos que, ungidos pela cultura desinteressada, votaram vidas e inteligências ao progresso do conhecimento. As metáforas religiosas se sucedem, pontuando os objetos sagrados: "sagração do exercício do magistério", "missão", "vocação do sacerdote", "profissão de fé", "templo", "religião da cultura paulista". 4

A sessão de formatura foi realizada a 25 de janeiro de 1937, pois o dia do aniversário da cidade já havia sido escolhido pelos mentores para marcar a fundação da USP e para compor o seu brasão, que traz, ao fundo, o Colégio dos Jesuítas e, à frente, uma árvore frondosa, a cujo tronco se enlaça uma faixa com os dizeres "Collegio 1554", e em cuja copa se inscreve, sobre as páginas de um livro aberto, "Universidade 1934". Na composição, a fundação da universidade reedita a da própria cidade, que, supostamente nascida de um colégio, mostrou neste seu primeiro ato a vocação e o fado de civilizar o país pela educação. A formatura da primeira turma se fez, pois, no dia 25 de janeiro, como cabia ao ritual de início de uma "era de renovação pedagógica" - como disse o diretor Almeida Prado. Mesquita Filho, em nome dos fundadores,

2 CARVALHO, Laerte R. de. O Brasil, a Cultura e a Universidade. O Estado de S. Paulo, $13 / 7 / 1969$.

3 DURKHEIM, Émile. As formas elementares da vida religiosa. O sistema totêmico na Austrália. Tradução de Paulo Neves. São Paulo: Martins Fontes, 1996, p. 22.

4 UNIVERSIDADE DE SÃO PAULO. Anuário da Faculdade de Filosofia, Ciências e Letras da Universidade de São Paulo (1936). São Paulo: Seção de Publicações da USP, 1937a. 
anunciou aos formandos: "Encerrastes definitivamente um ciclo da nossa existência, para dar início a outro: o da nossa maioridade cultural"5; assim dizendo, passou a falar-lhes do Brasil, da universidade e da missão dos egressos da FFCL.

O paraninfo lhes apresenta um panorama dos "estados de civilização" em convivência no território nacional: dos "agrupamentos primitivos" do Norte, ao "feudalismo" que se dilata de Nordeste a Sul, até o litoral do Sudeste, onde se encontram o Distrito Federal, São Paulo e parte de Minas Gerais, "único trecho de civilização industrial do complexo brasileiro", região que atingira "maturidade plena" e pela qual "integra-se o Brasil no número de países evoluídos e que emprestaram à civilização moderna o seu feitio diferencial". ${ }^{6}$

Traçado o panorama, pergunta Mesquita Filho: "pois bem, senhores, para se haver com essa trama quase inextricável de terríveis problemas, com que conta o brasileiro?" Responde que contara sempre com os liberais das faculdades de Direito, Medicina e Engenharia, instituições a que se resumira o ensino superior brasileiro em mais de um século de vida política independente. Teríamos vivido, até então, em "inacreditável estado de indigência cultural", que só começaria a ser rompida pelos professores formados na FFCL, a quem caberiam as tarefas de fazer progredir a ciência, produzindo trabalhos pessoais, e de dar exemplo aos estudantes, despertando neles "o gosto das pesquisas desinteressadas". ${ }^{7}$

Mesquita Filho já havia ventilado que um dos fatores determinantes do caos político do país residia justamente na ausência de uma elite intelectual capaz de compreender os problemas nacionais e dar a eles solução adequada. ${ }^{8}$ A tarefa de preencher esse vazio estaria reservada à universidade, pois somente com a formação de uma nova elite seria possível afastar do poder as oligarquias atrasadas, permitindo que os homens educados nos padrões cívicos, morais e intelectuais do liberalismo formulassem "o problema brasileiro". A eles caberia articular a coesão política a favor dos "interesses nacionais", pois nem a massa inculta, nem os políticos de visão tacanha, têm capacidade de identificá-los.

\footnotetext{
Idem, p. 198.

Idem, p. 199-200.

Idem, p. 200-203.

8 MESQUITA FILHO, Júlio de. A crise nacional. Reflexões em torno de uma data. São Paulo: Seção de Obras de OESP, 1925.
} 
Na universidade projetada por Mesquita Filho caberia à FFCL o papel de promover e divulgar a cultura livre e desinteressada, formando a elite de homens capazes de ver a sociedade sob o prisma do "interesse geral", e não sob o dos interesses imediatos de uma categoria profissional. Tal idéia encontra-se no cerne da organização da USP, em cuja estrutura a FFCL "assume o significado do lugar onde o conhecimento pode ser elaborado dentro de uma perspectiva de unificação dos interesses sociais", representando "a condição da conservação e reprodução do projeto de hegemonia cultural e política, de São Paulo e da Comunhão [Paulista], dentro da nacionalidade". ${ }^{9}$

Segundo Mesquita Filho, as finalidades para as quais surgira a FFCL eram as de formar os espíritos em condições de criar e praticar uma doutrina educativa que tivesse em vista assegurar a seleção de capacidades, de só pensar e fazer pensar "naquilo que moraliza, que não traz o lucro imediato, que leva o olhar a fixar-se alto e longe". ${ }^{10}$ Os fundadores pretendiam que esse foco de cultura desinteressada irradiasse para todo o país uma concepção nova, a combater a "velha e desagregadora idéia do saber pelo saber", substituindo-a pela idéia do "saber posto ao serviço da coletividade", e a dotar o país de um "cérebro poderoso e coordenador que, a coberto da transitoriedade dos governos, pudesse gerar o sentimento, a vontade, a organização e a disciplina intelectual a que os povos verdadeiramente fortes devem as suas melhores vitórias".

Para Mesquita Filho, os "espíritos tacanhos" de nossos homens de cultura, "simuladores" desprovidos de originalidade e de poder de penetração na realidade do país, acabaram por envolver o país nos resíduos alienígenas da crise "em que agonizam as nações do velho continente", uma vez que trouxeram para o Brasil "a contrafação das lutas em que na Europa se empenham, de um lado, os partidários do fascismo e, de outro lado, sectários do comunismo". Instilar na consciência coletiva a "mística nacional" é uma tarefa que o paraninfo atribui, mais do que aos licenciados, aos paulistas, "porque [...] o Brasil nada mais é do que um problema posto pelas bandeiras; e, ou nós, paulistas de hoje e de amanhã, o resolveremos, ou teremos irremediavelmente falido ante nossos antepassados". ${ }^{11}$ Mesquita Filho dava aos paulistas um lugar de

9 CARDOSO, Irene R. A Universidade da Comunhão Paulista. São Paulo: Cortez: Autores Associados, 1982, p. 156.

10 UNIVERSIDADE DE SÃO PAULO, op. cit., p. 204.

11 Idem, p. 205-206. 
destaque e liderança na Federação, pois de São Paulo deveria partir a regeneração política, missão superior que, destinada ao mais desenvolvido dentre os estados, justificava a submissão de todos os demais a seu "imperialismo benéfico" 12 , que retiraria a massa do estado inerme e faria com que ela seguisse o caminho aberto pelo bandeirante. ${ }^{13}$

Uma vez que era precisamente na FFCL que se pretendia formar a elite dirigente, depositava-se nela a essência do projeto político que Mesquita Filho representava. Ao mesmo tempo em que conferia aos formandos essa responsabilidade, o paraninfo thes dava motivos para se orgulharem de sua superioridade. Se os desavisados das primeiras turmas ainda não o sabiam, ficaram então sabendo; os que não estavam presentes à cerimônia foram, entretanto, lembrados pelos paraninfos e oradores de outras sessões solenes, que se encarregaram de revivê-lo.

A segunda metade da década de 1940 marcou o fim da Segunda Guerra Mundial, com a revelação das atrocidades cometidas pelos governos totalitários com os quais o regime de Vargas flertara, e pelo início da Guerra Fria, que repercutia no Brasil nas medidas de rompimento de relações diplomáticas com a União Soviética e de cassação do registro eleitoral (e logo depois, dos mandatos de seus parlamentares) do Partido Comunista do Brasil. A frustração, com a eleição de Eurico Gaspar Dutra, dos que alimentavam as expectativas de democratização, somava-se ao aspecto sombrio do quadro internacional, tocando o ambiente universitário e pontilhando as falas das sessões solenes da FFCL da USP.

No meio intelectual, um inquieto e amargurado Mario de Andrade promovia a revisão crítica do Modernismo e da geração de 1922 em intervenções de impacto como "A elegia de abril". O texto, não por acaso, fez-se publicar no número inaugural de Clima,

12 MESQUITA FILHO, Júlio de. A Comunhão Paulista. Revista do Brasil, n. 84, 1922, p.374-376.

13 A figura positiva do bandeirante, criada pelos historiadores do Instituto Histórico e Geográfico de São Paulo para representar a força civilizadora do povo paulista (cf. FERREIRA, Antonio Celso. A epopéia bandeirante: letrados, instituições, invenção histórica (1870-1940). São Paulo: UNESP, 2002), repetiu-se insistentemente nas sessões solenes da FFCL, desde o discurso de Mesquita Filho. Na formatura da turma de 1942, por exemplo, o paraninfo Jorge Americano assim exortou os bacharéis: "como eles, bandeirantes das selvas, nós, bandeirantes da cultura, somos chamados a estruturar a Pátria, dentro do continente, onde a civilização se salvará [...]. Bandeirantes da cultura, chegou a hora da definição cultural da América Latina [...]. Com a graduação de hoje, começa-vos a responsabilidade verdadeira, em que irradiareis o espírito universitário que temperastes" (UNIVERSIDADE DE SÃO PAULO, op. cit., p. 246). 
revista criada por um destacado grupo de alunos de mestres estrangeiros da FFCL que requisitava para si o legado modernista. ${ }^{14}$ Nelas, Mario critica o movimento e a geração de que era grande expoente, procurando mostrar as insuficiências e a inconseqüência do Modernismo diante do drama social da época, e pregando um corretivo "compromisso" para as gerações vindouras. A crueza da realidade do pós-guerra e a falência do projeto nacional estadonovista esgotavam o tempo da indiferença, da abstenção do artista diante da realidade social e exigiam do intelectual a observância de uma certa ética de comprometimento e, enfim, a sua participação, "não se sabe se politicamente ou de alguma outra maneira". ${ }^{15}$

A posição de Mario de Andrade, por tudo aquilo que passara a representar no campo cultural desde a eclosão do movimento modernista, não deixou de repercutir entre os aspirantes à condição intelectual. Ela aparece nas falas das sessões solenes da FFCL como desestabilizadora da idéia missionária original, à luz da qual os membros do agrupamento reformulam as orientações e mantêm a identidade, operando sobre os "objetos sagrados" de modo a unificar presente e passado.

A turma de 1950 escolheu como orador Dante Moreira Leite, que no discurso se define, e aos jovens de sua época, pela "ausência de finalidade distante", a que faz com que os homens se apeguem às tarefas imediatas, todavia, não às mais necessárias. Esse comportamento justifica-se diante de um quadro geral de indefinição:

É que, se todos sentimos a inutilidade dos velhos caminhos, já agora incapazes de satisfazer às necessidades e aspirações humanas, sentimos também que ainda não encontramos o novo caminho por onde seguir e por onde levar conosco os nossos alunos e os mais jovens que nós. ${ }^{16}$

14 Lahuerta cita duas intervenções de Mario de Andrade, de teor semelhante ao de "elegia": a conferência "O Movimento Modernista" (1942), no Itamaraty, e "A arte de servir" (1944), entrevista dada para a revista Diretrizes (LAHUERTA, Milton. Os intelectuais e os anos 20: moderno, modernista, modernização. In: DE LORENZO, Helena Carvalho; COSTA, Wilma Peres da [orgs.]. A década de 1920 e as origens do Brasil moderno. São Paulo: UNESP, 1997). Sobre o grupo Clima como herdeiro do modernismo, ver PONTES, Heloísa. Destinos mistos. Os críticos do Grupo Clima em São Paulo, 1940-1968. São Paulo: Companhia das Letras, 1998.

15 LAHUERTA, op. cit., p. 113.

16 UNIVERSIDADE DE SÃO PAULO. Anuário da Faculdade de Filosofia, Ciências e Letras da Universidade de São Paulo (1950). São Paulo: Seção de Publicações da USP, 1952, p. 71. 
Os velhos caminhos não poderiam ser seguidos, é certo, mas não havia por onde ir e para onde conduzir as novas gerações. Diante do impasse, entra em cena o intelectual, cuja condição e cujo papel na idade contemporânea deveriam assumir novas configurações:

Daí a necessidade [...] de distinguir entre informação e propaganda: pois, ao que tudo indica, não lemos nem ouvimos informações dadas para o julgamento do povo, mas temos simplesmente a propaganda, voluntária ou involuntária, que arrasta os homens para um lado e para outro, ao acaso dos temores fundados ou infundados, ou dos interesses legítimos ou ilegítimos dos dirigentes políticos dos diversos povos. [...]. A conseqüência dessa ordem de coisas é que passamos a lutar por palavras cujo verdadeiro sentido ninguém será capaz de nos explicar; passamos a lutar por falsos ideais e falsas aspirações. ${ }^{17}$

O jogo insistente de oposições indica o alto grau de indefinição, diante, especialmente, da complexidade da situação internacional, que confluía para a divisão do mundo em duas partes. O sentimento de impotência e de desesperança com relação ao futuro trazia dúvidas sobre o sucesso da profecia anunciada pelo paraninfo da primeira turma, ao impor aos formandos de 1950 a crua realidade das décadas passadas, em que se mostrara como a manipulação das massas havia-se convertido em instrumento político a serviço dos governos.

Diante da propagação de "falsos ideais" e "falsas aspirações" pelos veículos de comunicação de massa, o intelectual deveria assumir o papel de juiz, promovendo a distinção fundamental entre informação e propaganda. Ao dizer isto, Leite provavelmente se reporta ao discurso do paraninfo da turma de 1948, Lívio Teixeira, em que este conclamara os formandos a compor uma geração de "verdadeiros intelectuais", ou seja, capazes de

compreender até que ponto nossas idéias, as idéias que temos como verdadeiras e como princípios fundamentais da nossa vida, podem ser determinadas pelo meio em que vivemos, pela classe a que pertencemos. [...]. Compreendê-lo, é tornarmo-nos verdadeiramente conscientes e capazes de entender o mundo em que vivemos, capazes de julgar, de discriminar entre o que deve e o que não deve ser conservado. ${ }^{18}$

17 Idem, p. 71.

18 UNIVERSIDADE DE SÃO PAULO. Anuário da Faculdade de Filosofia, Ciências e Letras da Universidade de São Paulo (1939-1949). São Paulo: Seção de Publicações da USP, 1953a. p. 295. 
O "verdadeiro intelectual", para Teixeira, deve ser o homem de vasta e elevada cultura geral que se volta para o mundo em que vive a fim de julgar o que é e o que não é bom. É justamente a conjugação de suas capacidades ao grau de comprometimento com a delegação social que o distingue das figuras do "simples erudito", descomprometido com os rumos do mundo, e do "intelectual cooptado", que, chamado a participar do Estado, compromete-se com o regime e sua propaganda. ${ }^{19}$ Essa tarefa de ajuizamento, que dava ao intelectual a responsabilidade de guiar a sociedade para a democracia e o desenvolvimento, transcendia a lida com as ciências e as interlocuções estritamente acadêmicas para atingir as massas, mediante presença na educação e nos canais de comunicação, uma vez que "os verdadeiros intelectuais são homens de idéias claras e não de ideologias" ${ }^{20}$

Os intelectuais da FFCL, "bandeirantes da cultura", exortados a assumir cargos políticos e técnicos para promover a condução racional do país ao desenvolvimento econômico e à democracia, neste momento atribuíam a si a tarefa de ocupar, para o bem público, os lugares de onde poderiam ofertar ao povo a leitura autorizada da realidade social, acompanhada pela indicação dos bons caminhos a seguir para a realização daqueles fins primordiais. ${ }^{21}$

De forma provocativa, Mesquita Filho iniciara sua fala na sessão de formatura da primeira turma anunciando que o ato de entregar diplomas aos licenciados da nova faculdade era especial e não se igualava ao "ato banal e corriqueiro" pelo qual os formados em Direito, Medicina ou Engenharia eram considerados aptos a exercer suas profissões. Com isso, lançava às "faculdades tradicionais" tremendo insulto, apequenando os seus diplomas diante dos que ora se emitiam na FFCL. Para além do teor pessoal da crítica

19 Para Lahuerta, o Estado Novo teria acolhido os intelectuais para os organismos estatais especialmente criados para que desempenhassem a função de "partido nacional de governo", ou seja, a de promover a organização da sociedade, da cultura, da economia e do direito modernos. Para o autor, este movimento não poderia ser propriamente caracterizado como de cooptação, "mas de constituição de um novo bloco de poder com uma simultânea perspectiva autoritária e modernizadora, que busca consenso entre a intelectualidade chamando-a para participar do processo, realizando a fusão de modernidade e projeto nacional" (LAHUERTA, op. cit., p. 106).

20 UNIVERSIDADE DE SÃO PAULO, p. 295, 1953a.

21 Tal consciência explica o investimento das primeiras gerações de formados na FFCL na carreira jornalística. Em 1946, o jornal O Estado de S.Paulo contratou para a redação de sessões especializadas os licenciados Décio de Almeida Prado, Lourival Gomes Machado e Laerte Ramos de Carvalho. 
de um ex-aluno aos modos das Arcadas, o conteúdo e a intensidade das palavras de Mesquita Filho e, principalmente, seu impacto entre os presentes à solenidade, não só abarcavam questões mais relevantes, de que as maneiras bacharelescas eram tidas como sintoma, como respondiam à resistência das escolas incorporadas à idéia de uma universidade cujo centro fosse a Faculdade de Filosofia, Ciências e Letras.

O discurso de paraninfo é, dessa forma, uma peça de guerra nas mãos do mentor e defensor desse modelo de ensino superior contra os interesses dos grupos por ele ameaçados, dentre os quais figuravam os que se opunham à tradição bacharelesca, mas que tinham seus próprios projetos de renovação e modernização das elites dirigentes, tais como os politécnicos, por exemplo. Esse discurso criou raízes, foi repetido e adotado pelos estudantes, produzindo a representação de que a FFCL foi vítima de incompreensão de "interesses mesquinhos" das outras faculdades, de "ciúmes" dos professores nacionais diante dos mestres da missão estrangeira, ou mesmo de "ignorância" generalizada sobre o que a instituição universitária representava para a cultura e o desenvolvimento nacionais.

A referência a esse tema retornou em 1951, por um dos diplomados em 1936, Eurípedes Simões de Paula, agora paraninfo. Para o catedrático, Mesquita Filho lançara "lenha na fogueira" ao proferir um discurso contendo "algumas verdades amargas [...], que causou grande repercussão e deu origem a grandes lutas para a nossa Faculdade", das quais ela ainda não teria se desvencilhado. ${ }^{22}$ Referia-se, no passado, à expulsão dos estudantes de Ciências Naturais do prédio da Faculdade de Medicina, onde estavam provisoriamente alocados, e à reação dos professores da Escola Politécnica à medida de centralização das cátedras, que concentrava as disciplinas básicas de todos os cursos da universidade na FFCL, e as retirava dos professores das escolas incorporadas, para entregálas aos professores estrangeiros. ${ }^{23}$ Referia-se, ainda, à contrariedade dos professores nacionais, preteridos diante dos mestres es-

22 UNIVERSIDADE DE SÃO PAULO. Anuário da Faculdade de Filosofia, Ciências e Letras da Universidade de São Paulo (1951). São Paulo: Seção de Publicações da USP, 1953b, p. 52-53.

23 Sobre a polêmica envolvendo a FFCL e a Escola Politécnica de São Paulo, ver Um conflito entre a Congregação da Escola Polytecnica e o Conselho Universitário da Universidade de São Paulo perante o Conselho Nacional de Educação. São Paulo: Revista dos Tribunais, 1937. 
trangeiros que vieram ocupar as cátedras. ${ }^{24}$ Quanto aos fatos do presente, certamente referia-se ao impasse provocado em razão da polêmica anulação das candidaturas de pretendentes externos à Cadeira de Filosofia, em sua grande maioria vinculados ao Instituto Brasileiro de Filosofia e a Miguel Reale, em benefício do professor da casa, Cruz Costa. ${ }^{25}$

$\mathrm{O}$ que havia de comum nessas manifestações, e que era traduzido nas sessões rituais como "incompreensões" das altas aspirações dos bandeirantes da cultura, portanto, como ignorância e mesquinhez diante dos benefícios civilizatórios das iniciativas em prol do controle da produção de ciência e da formação cultural pela FFCL, era a demonstração de que os ideais do grupo de Mesquita Filho não eram consensuais em todos os círculos da elite ilustrada paulista, cujas frações, em defesa de suas respectivas instituições, reagiram à imposição unilateral de uma "integração universitária" pela qual fossem submetidas à Faculdade de Filosofia. Essa reação, diferentemente da interpretação pretendida na FFCL, não era motivada por conservadorismo e apego ao passado, mas pela pretensão dos grupos rivais em tornar viáveis os seus próprios projetos de modernidade, dos quais as instituições de ensino superior eram portadoras.

A Escola Politécnica de São Paulo, por exemplo, acusada de ser retrógrada por resistir à centralização das cátedras, ensaiara o seu próprio projeto universitário no início dos anos 1930, ao incorporar em seu regulamento profundas inovações:

24 Foge ao escopo deste artigo o aprofundamento da reação aos professores estrangeiros, que na memória da FFCL figura como produto de "ciúme" dos incompetentes professores nativos (ver, por exemplo, Estudos Avançados, São Paulo, v. 7, n. 18, 1994). Em tese de doutoramento, procurei desenvolver o tema, apoiando-me em Patrick Petitjean, para quem todo o processo de escolha, transferência e permanência dos mestres franceses em São Paulo apresenta-se crivado de acasos e conflitos, em contraste com a idílica memória perpetuada por seus ex-alunos (cf. PETITJEAN, Patrick. As missões universitárias francesas na criação da Universidade de São Paulo [1934-1940]. In: HAMBURGER, Amélia Império et alii [orgs.]. A ciência nas relações Brasil-França [1850-1950]. São Paulo: Edusp/Fapesp, 1986, p. 259-330).

25 A FFCL abrira em 1951 o concurso para Cadeira de Filosofia, tendo em Cruz Costa, que já a ocupava, um candidato natural. Entretanto, quatro membros do IBF se inscreveram, ao que as autoridades responsáveis pela FFCL responderam com a impugnação da inscrição de todos os concorrentes, sob a alegação de que não apresentavam em seus currículos o estudo de Filosofia. Ao lançarem mão de um parecer de Almeida Júnior, no qual se defendia não ser Filosofia a Filosofia do Direito que os candidatos traziam de seus cursos jurídicos, mas apenas uma parte integrante da Ciência Jurídica, as autoridades da faculdade contra-atacaram a ofensiva em massa do grupo do IBF à vaga posta em concurso. 
O decreto de 1931, ao lado da manutenção dos diferentes cursos de engenharia que abrangia os mais diversos campos de conhecimento - da química à arquitetura, da mecânica à eletricidade - objetivava transformar a Escola Politécnica em um centro de pesquisa e de ensino no ramo científico, englobando desde o campo da Matemática, na qual já era reconhecidamente um dos grandes irradiadores, até a Física e a Química. Abrangia ainda os campos da Geologia e da Mineralogia, nos quais não possuía maior tradição. Movimento nesse sentido deve ter sido feito, tanto que no ano seguinte foi baixado o decreto federal 21.303 (18 de abril) que autorizava a criação da Universidade Técnica de São Paulo, cujo núcleo seria a Politécnica. ${ }^{26}$

Essa idéia, nada retrógrada, foi vencida justamente quando da instalação da USP, dois anos depois do decreto federal. Até então, a Poli orgulhava-se de ser a única escola superior que detinha o saber "positivo", "verdadeiro", e a decorrente responsabilidade de superar o atraso crônico em que o país se encontrava. Ainda de acordo com Nadai, parafraseando os professores Álvaro de Menezes e Alexandre de Albuquerque, "daí seus alunos se atribuírem a missão de 'soldados do progresso' empenhados na 'Grande Cruzada', que em nome da 'Sciencia' penetraria no 'Grande Mundo'. Por esse imaginário, ela representava o 'moderno' em oposição à outra instituição tradicional de ensino superior - a Faculdade de Direito de São Paulo". ${ }^{27}$

É notável a semelhança entre os discursos de politécnicos e "filósofos": em ambos aparece a idéia de missão em nome da ciência e da modernidade, tendo como adversários os bacharéis e como quimera o alinhamento ao mundo civilizado. No caso dos filósofos, o saber considerado mais importante para a formação das elites e, conseqüentemente, para a condução da política, era o "conhecimento científico da sociedade", detido pelo sociólogo. Por isso, tal pensamento engendrava, necessariamente, um modelo universitário em que a FFCL ocupava lugar destacado, pois "nela se formariam os cientistas sociais responsáveis pelo equilíbrio do organismo social". ${ }^{28}$ Já na Escola Politécnica de São Paulo, assim como na do Rio de Janeiro e na Escola de Minas de Ouro Preto, a idéia de produzir elites "modernas" e dotadas de conhecimentos científicos

26 NADAI, Elza. Ideologia do progresso e ensino superior (São Paulo 1891-1934). Tese de doutoramento. Faculdade de Filosofia, Letras e Ciências Humanas da Universidade de São Paulo, 1981, p. 89.

27 Idem, p. 123.

28 CAPELATO, Maria Helena R. Os arautos do liberalismo. Imprensa paulista 1920-1945. São Paulo: Brasiliense, 1989, p. 145. 
fez prevalecer outro modelo, dito politécnico, que marca "o projeto de formação e a consolidação de uma elite técnica e científica capaz de responder a uma perspectiva de modernização, então em curso na vida brasileira, ainda sob o regime imperial". ${ }^{29}$ Para Isidoro Alves,

formar e graduar engenheiros (civis, industriais, de minas etc.) implicava a criação de um sistema que pudesse estabelecer hierarquias de saberes e, também, um novo modelo de reprodução que introduzisse na cena intelectual outros atores que não os bacharéis e literatos. Na medida em que o Estado passa a atuar como força dirigente na remodelação física dos centros urbanos emergentes, os engenheiros logo exerceriam o seu papel no boom experimentado pela engenharia nacional nas últimas décadas do século XIX. Para além de um engenheiro, tratava-se de formar um politécnico, ou seja, tratava-se de construir uma categoria sociologicamente consistente e que pudesse intervir como instância identificadora. ${ }^{30}$

A modernização, tomada como objetivo indiscutível e tarefa dignificante, não era assunto e interesse exclusivo da elite responsável pela criação da USP, mas dos grupos que desde os fins do século XIX lutavam pela unção, por parte da ciência e do Estado, de diferentes projetos de formação das elites dirigentes. Essa luta, que se traduziu em disputas por modelos de ensino e de formação e pela definição de uma hierarquia de saberes, opôs politécnicos, médicos e "filósofos", que se insultavam mutuamente usando termos como "velho", "tradicional" e "retrógrado". No recinto de cada uma delas, é claro, "novo" era um atributo exclusivo.

O estado de permanente alerta contra o inimigo externo aparece na memória dos ex-alunos da FFCL na recordação do Estado Novo, em que se teria tentado destruí-la. O ex-aluno e ex-professor Erasmo Garcia Mendes explica que a nomeação de Adhemar de Barros para a interventoria em São Paulo teria afetado diretamente a escola, pois o perrepista "não via com bons olhos a criação de Armando, isto é, a FFCL. Nisso, era acompanhado por outros setores da sociedade conservadora, entre os quais a Igreja, que julgava essa faculdade um antro de ateísmo". ${ }^{31}$

29 ALVES, Isidoro Maria da S. Modelo politécnico, produção de saberes e a formação do campo científico no Brasil. In: HAMBURGER, Amélia Império et alii (orgs.). A ciência nas relações Brasil-França (1850-1950). São Paulo: Edusp/Fapesp, 1986, p. 65.

30 Idem, p. 67.

31 PAVAN, Crodowaldo; CUNHA, Brito da; MENDES, Erasmo Garcia; COELHO, Marco Antônio. Faculdade de Filosofia da USP: lições inesquecíveis. Estudos Avançados, São Paulo, vol. 7, n. 18, p. 206, 1994. 
Com efeito, Adhemar de Barros nomeou para a direção da FFCL um dos mais antigos e ferrenhos inimigos da instituição, Alexandre Corrêa. Disposto a modificar os contratos, suprimindo as cláusulas que previam reajustes de salário, o católico da Faculdade de São Bento também teria tido a intenção de desdobrar a Cadeira de Filosofia, a fim de nela introduzir o ensino de Santo Tomás de Aquino. Embora a memória da FFCL conte que Alexandre Corrêa fora nomeado com o objetivo de cerrar-lhe as portas, o fato é que nenhuma de suas iniciativas ameaçou seriamente a sobrevivência da instituição, a não ser que se considere com tais o esmero em dificultar a vida dos mestres franceses e o desejo de alterar as diretrizes da Filosofia ensinada, então a cargo de Jean Maugüé, um protestante francês esquerdista, ligado à Frente Popular. De todo modo, a memória da FFCL registra que, quando os alunos de Jean Maugüé apoiaram ostensivamente a manutenção do cargo de seu professor, Corrêa demitiu-se ${ }^{32}$ - em ato de pouca perseverança, da parte de quem havia sido incumbido de tão grave missão.

Da mesma forma, a memória registra que Alfredo Ellis Jr., um nacionalista, fora nomeado diretor da FFCL com o propósito de "liquidar" a instituição ou, ao menos, substituir os professores estrangeiros por nacionais. Não fez isto e nem aquilo, e a explicação corrente para o "fracasso" de sua iniciativa é bastante curiosa: segundo Ruy Coelho, "Alfredo Ellis tomou contato com os estudantes e mudou radicalmente de posição". ${ }^{33}$ Já Erasmo Garcia Mendes argumenta que a instituição foi salva da extinção ordenada por Adhemar de Barros graças à intervenção heróica de um de seus mestres estrangeiros em certa reunião do Conselho Universitário, havida numa manhã do ano de 1938, na Faculdade de Direito:

Para essa reunião foram convidados os professores [Ernest] Marcus e Luigi Fantappié. A proposta de se destruir a FFCL só não teve êxito porque, segundo me contou o professor Marcus, Fantappié emudeceu os conselheiros com uma brilhante defesa dos objetivos da Faculdade, mostrando que sua extinção seria um inconcebível retrocesso em termos culturais e científicos. Assim, o grande matemático italiano salvou a FFCL. ${ }^{34}$

32 PETITJEAN, op. cit., p. 324-325.

33 Apud PETITJEAN, op. cit., p. 325.

34 PAVAN et alii, op. cit., p. 206. 
Chama a atenção o fato de que Fantappié, membro do partido fascista desde $1912^{35}$, para quem os mentores da USP, mais tarde declarados anti-fascistas, haviam reservado uma cadeira que, segundo os próprios, não "ensina a pensar", tivesse um prestígio tão grande no Conselho Universitário. Alegar-se-ia que influências políticas no ambiente do Estado Novo teriam levado um fascista a tal condição, mas apenas se a posição que Fantappié tomou no Conselho Universitário não tivesse sido contrária ao desiderato do interventor; e se o mesmo Fantappié não tivesse sido escolhido, em 1936, para ser relator de um anteprojeto de reforma estrutural da faculdade, no qual se propunha a separação das faculdades de ciências das de letras e filosofia. Para quem não podia "ensinar a pensar", a presença do fascista Fantappié na definição dos rumos dessa instituição liberal é bem destacada.

A propósito, a filiação de Fantappié ao partido fascista não costuma aparecer nos depoimentos dos mentores e dos ex-alunos da FFCL, assim como a de Francisco Piccolo, professor de literatura italiana, fascista desde 1922. A esse respeito, Paulo Duarte respondeu à Ciência Hoje:

[Ricardo Guedes (UFMG)]: É verdade que eles [os italianos] vinham, recebendo pelo partido fascista?

[Paulo Duarte]: Não, não. Não tinha nenhum fascista. Todos eles eram neutros ou esquerdizantes. Mas não teve nenhum fascista. Isso nós evitamos com muito cuidado. Porque eu já era raivosamente antifascista. E o Julinho também.

[Ricardo Guedes (UFMG)]: E mantinham um vínculo oficial com o Governo italiano?

[Paulo Duarte]: Mantinham, mas por burocracia, por assim dizer. Nunca fizeram política aqui. Nunca houve uma conferência desses italianos que fosse tendenciosa.

[Ricardo Guedes (UFMG)]: Nem o Fantappié?

[Paulo Duarte]: Nem o Fantappié, absolutamente. O Fantappié só fez Matemática. ${ }^{36}$

As fontes que Petitjean reuniu não dizem o mesmo. De acordo com o autor,

o primeiro curso de Piccolo suscita diversos embaraços: ele faz a apologia do fascismo e de Mussolini. Paulus Aulus Pompéia conta

35 PETITJEAN, op. cit., p. 263.

36 DUARTE, Paulo. A criação da USP segundo Paulo Duarte. Ciência Hoje, vol. 3, n. 13, p. 40-44, jul-ago 1984. 
também que Fantappié "chegava da rua, levantava a mão e fazia a saudação fascista". Mesmo Wataghin faz a saudação fascista durante o primeiro curso, mas não a repete mais. Fantappié era responsável pelo grupo fascista, e somente Wataghin e Occhialini não assistem às reuniões do grupo. ${ }^{37}$

Durante o Estado Novo, importantes espaços passaram a se abrir na FFCL para os inimigos da escola, notadamente para os católicos, nacionalistas e anticomunistas, que se agregavam ao já complexo agrupamento de liberais, socialistas, comunistas e fascistas. Talvez por não se ter batido contra esse movimento, a FFCL manteve-se em pé, ao contrário do que ocorreu com o Instituto de Educação, este sim, tido como inútil por professores como Fantappié. ${ }^{38}$

Como se deu, afinal, o relacionamento da FFCL com o Estado Novo, que supostamente a pretendia extinguir? Não há como responder, embora haja bons indícios dessas relações nas sessões solenes da FFCL, manifestos nas escolhas de paraninfos e em certas falas de professores e alunos oradores.

Em 1938, os trabalhos da escola haviam-se iniciado com a Aula Inaugural do catedrático de Biologia Geral, André Dreyfus, primeiro professor brasileiro contratado para a FFCL. Diante da presença das autoridades do estado, encabeçadas pelo interventor Adhemar de Barros, o professor não deixa de lhes creditar a manutenção da escola:

Graças ao atual governo, representado por Suas Excelências, os srs. Governador do Estado e Secretário da Educação e Saúde Pública, foi sabiamente mantida na Universidade essa instituição que é a verdadeira garantia do progresso da pesquisa científica em São Paulo. ${ }^{39}$

37 PETITJEAN, op. cit., p. 264.

38 O mencionado anteprojeto de 1936, apresentado à Congregação, do qual Fantappié era relator, propunha a redução da FFCL às seções de Letras e Ciências, e a criação de um "Seminário Pedagógico", destinado a preparar os bacharéis para que se candidatassem aos diplomas de habilitação do magistério secundário. O anteprojeto já dispensava, portanto, o Instituto de Educação, excluindo as matérias componentes de seu currículo na formação do professor secundário pela Faculdade de Filosofia. Essa proposta expressava o pensamento da maioria dos professores estrangeiros, contrários às disciplinas pedagógicas, para os quais bastava a formação científica de qualidade para que o professor tivesse condições de operar a transformação do conteúdo aprendido em conteúdo a ser ensinado nas escolas normais e secundárias.

39 UNIVERSIDADE DE SÃO PAULO. Anuário da Faculdade de Filosofia, Ciências e Letras da Universidade de São Paulo (1939-1949). São Paulo: Seção de Publicações da USP, 1953a, p. 68. 
Com efeito, durante o Estado Novo, verifica-se que nenhuma lei ou decreto estadual veio prejudicar a FFCL, como muitos esperavam que acontecesse com a nomeação do interventor. Muito ao contrário, como se deu com a aprovação, pelo legislativo paulista, do Regulamento da FFCL, em 1941, os poderes estaduais ouviram e atenderam os interesses daquela escola, conforme revela Dreyfus, em 1942, diante das autoridades presentes à sessão solene:

Conforta-nos sobremodo ver como o Governo de São Paulo, a quem neste momento estamos homenageando, mostrou compreender $\mathrm{o}$ alcance do que cabe à nossa Faculdade empreender, e estamos certos de que continuaremos a ser ouvidos e atendidos, pois, se muito já foi realizado, bastante ainda resta a fazer para que a Faculdade possa cumprir integralmente suas finalidades. ${ }^{40}$

Não parece uma mera formalidade de anfitrião, a julgar pela ênfase com que em seguida Dreyfus refere-se ao Governo de São Paulo:

Voltaire, analisando a constituição chinesa, considera-a a mais sábia de todo o Universo, pois castiga o administrador que ao deixar o cargo, não for aplaudido pelo grande público. O que já tendes feito, Senhores administradores aqui presentes, é uma garantia de que ainda quando nos regesse a constituição chinesa dos bons tempos, nada teríeis a temer! ${ }^{41}$

Talvez por compreender o recado, no ano seguinte a Assembléia estabeleceu novos vencimentos para professores e assistentes da USP e aprovou o Regimento de Concurso para provimento dos cargos de professor catedrático e livre-docente da FFCL da USP. Foi, aliás, apenas em 1944, já nos estertores do regime, que um decreto-lei dispôs a subordinação da USP à Interventoria Federal.

Tendo atribuído ao entendimento, pelas autoridades, dos altos desígnios da universidade e da faculdade que supostamente desejavam fechar, Dreyfus ainda argumenta em favor da neutralidade da ciência, com o que o parece contornar problemas políticos. Na Aula Inaugural de 1938, concluíra deste modo uma digressão sobre o assunto:

As descobertas científicas, dando poder ao homem, dão-lhe, por isso mesmo a possibilidade de fazer o mal e assim, se a microbiologia e a

40 Idem, p. 98.

41 Ibid. 
química hão de ser desde logo condenadas, pois a guerra química já existe e a bacteriológica, ao que parece, virá breve, os demais departamentos da Ciência também forneceram, fornecem ou fornecerão armas mortíferas. Assim sendo, nenhum instrumento, nenhuma técnica deveria ser entregue à eterna criança que é o homem, pois tão depressa deles se apoderam, os utilizará contra os seus semelhantes. [...]. Não me cabe discutir o aspecto social deste problema, mas apenas afirmar que sobre a ciência não pode recair a culpa do mau emprego que, infelizmente, se tem tão largamente feito de suas descobertas. ${ }^{42}$

A ciência aparece como um bem necessário e neutro, cuja destinação respeita apenas aos critérios éticos de um "homem" abstrato. Tal opinião é reafirmada em 1942:

A Ciência em si não é nem boa, nem má. É neutra. Cabe ao homem utilizá-la no bom sentido. Ninguém condenará a faca, pela simples razão de cortar-se, com ela, a criança, ou usá-la para o crime, o tarado. Cabe à humanidade não teimar em permanecer em um desses dois estados. ${ }^{43}$

$\mathrm{O}$ argumento em favor da neutralidade e, portanto, do caráter apolítico da ciência pura, parece adequar-se ao momento em que assombrava a todos o destino que os países industrializados, em guerra, vinham dando à ciência e à tecnologia. Entretanto, no âmbito local, proferido diante dos representantes de um regime que prezava o controle das mentes pela propaganda ideológica e cooptação de intelectuais, o discurso de Dreyfus cuida da própria sobrevivência da FFCL, fazendo calar o discurso político que animara a sua própria criação. Se o discurso do mestre era apaziguador, isso também se devia ao fato de os próprios alunos se mostrarem gratos, o que se expressa no gesto da turma de 1940, que escolheu "o senhor A. de Barros", inimigo figadal da família Mesquita, para paraninfo.

Na sessão de formatura, Adhemar de Barros não desperdiçou a oportunidade. Em discurso habilidoso, fez vibrar as palavras que soavam bem naquele recinto:

Deixais os bancos de uma Escola que, apesar de ser ainda muito jovem, tem prestado à cultura paulista serviços de extraordinário valor. [...]. Ser-me-ia fácil desenvolver diante de vós o meu conceito pessoal sobre a função das Universidades. Entendo, por exemplo, que 
estas têm de ser formadoras de elites intelectuais. Não lhes basta preparar o homem para o exercício de uma profissão. Devem elas, além disso, formar o homem para o mais árduo dos seus ofícios, que é justamente o ofício de homem, no seio da sociedade contemporânea, sob o patrocínio da civilização imortal. Precisamos de profissionais liberais, de técnicos e de pesquisadores, não há dúvida nenhuma. Mas precisamos, antes de mais nada, de homens, ou seja, de indivíduos que não se contentem com a erudição livresca, senão que façam do livro simplesmente um guia para as suas indagações pessoais. ${ }^{44}$

É notável semelhança deste com o discurso de Mesquita Filho, para sempre lembrado como um "manifesto político" da USP. Os quinze anos de sua existência são enlaçados harmoniosamente por Adhemar de Barros quando, finalizando o discurso de 25 de janeiro de 1941, toma posse da história da cidade e da FFCL, manipulando desta forma as figuras evocadas em 1937:

A vossa festa de formatura coincide com duas datas memoráveis: a fundação da Faculdade de Filosofia e a fundação de São Paulo. Com relação à primeira, já vos disse tudo o que eu penso. A minha presença nesta solenidade é, por outro lado, um testemunho insuspeito do alto apreço em que vossa escola é tida nas esferas governamentais. Tendo sido a última a chegar, força é reconhecer que em breve tempo se integrou no concerto das demais escolas universitárias, fazendo-se digna das tradições que enfeitam o passado das irmãs mais velhas. Quanto à fundação de São Paulo, tenho certeza de que comungais comigo no entusiasmo que a grande data nos inspira. São Paulo é, no Brasil, uma das mais belas realizações do esforço, do carinho e da tenacidade dos homens. Os primeiros jesuítas que escalaram as montanhas, vencendo as surpresas e as insídias da floresta virgem, fincaram no planalto um marco indestrutível. Fundaram uma cidade e moldaram um temperamento. Ergueram o Brasil nas mãos e o colocaram no alto, a dominar as distâncias e os homens. Deram-nos uma cruz e um livro, como a quererem significar, por certo, num milagre de intuição, que São Paulo haveria de crescer dentro da fé, sob a proteção da inteligência. Os séculos, nas vidas dos povos, contam muito poucos. São Paulo, não obstante, tem sabido aproveitar o tempo. A sua situação hoje, dentro do Brasil unido e próspero, uma situação inegável de domínio absoluto de todas as forças morais, intelectuais e materiais, tanto que a data natalícia da cidade assume hoje as proporções de verdadeira festa nacional. Haveis de ter sentido, com efeito, como eu tenho sentido, o calor e a intensidade do afeto que nos rodeia em nossa grande Pátria. ${ }^{45}$

44 Idem, p. 243.

45 Idem, p. 244. 
Em lugar do bandeirante, o jesuíta. Em lugar do choque entre "tradição" e "modernidade", a harmonia das escolas que compõem a universidade. Em lugar do "imperialismo" paulista, uma superioridade moral aplaudida pela "Pátria". O discurso de Adhemar de Barros traduz o significado da FFCL nos termos mais adequados ao regime, reforçando a herança cristã, a união nacional e o desejo de harmonia e paz social. A intervenção do "profano" no mundo do "sagrado" consumava-se, assim, pela apreensão das palavras e do direito de proferi-las, manifestando aos membros da "igreja" a sua necessária submissão à ordem de coisas mundanas que vigia para além de seus muros.

Recebido em 5 de março de 2008. Aprovado em 2 de setembro de 2008. 